\title{
An Empirical Study on the Relationship between Executive Compensation and Corporate Performance Man-Xue CHEN ${ }^{1, a,{ }^{*}}$, Chun-Xiao ZHANG ${ }^{1, b}$, Kang-Yin LU ${ }^{1, c}$ \\ ${ }^{1}$ School of Business, Northeast Normal University,P.R.China, 130117

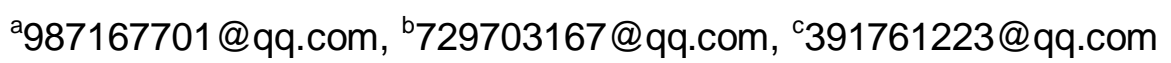 \\ ${ }^{*}$ Corresponding author
}

Keywords: Sustainable growth rate, Executive compensation, Corporate performance.

\begin{abstract}
China's stock market has changed dramatically since the non-tradable share reform in 2006. At this new macro-economic background, this paper is based on the new financial concept which is under the guidance of the sustainable development theory. The paper re-examine the relationship between corporate performance, executive compensation, executive shareholding, inspecting remuneration and corporate performance with a different view, in order to find out some enlightenment. The result shows that: corporate performance, executive compensation and executive shareholding are dramatically correlated. According to the empirical findings, the paper made some suggestions for the design of China's listed companies pay system.
\end{abstract}

\section{Introduction}

Listing Corporation, as an outstanding group in China, is the most important part of China's economic entity. Especially, China's stock market has changed dramatically after the non-tradable share reform. Listing corporations have also been unprecedented attention, and their operating performance is the focus of public concern. At the same time, the institutional investors, such as general fund company, increase enormous in the wave of the bull market, which deeply affect Chinese stock market. Their appearance reduces stock's speculative atmosphere, thus promoting the rational investment concept of development and the long-term development of the stock market. Investment philosophy change will produce a chain reaction of listed companies.

Meanwhile, since China begin the disclosure of listed company executive pay in 1998, executive compensation has been the attention of the scholars and the public widely. Compensation system is an important part of corporate governance, which has a great influence on corporate performance. Currently, China's executive compensation exist many problems in quantity, structure and mode, affected by the economic environment, social culture, corporate governance structure, internal conditions and many other factors. Especially the lack of effective long-term incentive mechanism, thus appeared the serious "insiders control" and "59-year-old phenomenon", which indicates that China's enterprise management incentive system exists serious short-coming and weak incentive constraint. So to study the rationality of listed companies' executive compensation incentive not only can improve managers' performance, but also can maintain the core rights of enterprise owner.

\section{Literature Review}

The relationship between executive compensation and enterprise performance are the hot spot of western scholars' research. Since the 1960s, studies in this area using empirical methods attracted the attention of more scholars. Researchers used different ranges of data in different periods for different studies. Conclusions of them are different and some even conflict. 
BARRO[1](1990) studied the relationship between manager salary and enterprise scale. Conclusions of the study showed that: there was a strong positive correlation between the manager salary and enterprise scale.

Garen[2](1994) had established a model based on the Principal-agent theory to study the determinants of manager salary level and structure. He found the manager salary structure was the conclusions for the balance of incentives and risk, which was consistent with standard principal-agent theory. In addition, his empirical analysis found that in the company's compensation structure, relative performance compensation issue seemed not to be considered by most companies.

Mehran[3] (1995) used the data of a random sample of 153 manufacturing companies from 1979 to 1980 , to conduct an empirical study between salary structure of managers and company performance. His research conclusions showed that the company's performance had positive correlation with CEO's stake, as well as the equity-based salary proportion in CEO's salary.

From the domestic research situation of China, we could find that since listed companies began to disclose executive compensation in its annual report in 1998, many scholars took China's listed companies as samples. They did empirical test on the relationship between executive pay and corporate performance. The conclusions were also different.

Gang Wei[4] (2000) took 816 A-share listed companies in Shanghai and Shenzhen stock market as samples, using annual data in 1998 to investigate the relationship between senior management incentive and the business performance. He also examined the annual remuneration of senior management as well as the size of listed company. The conclusion was that there was no significant positive correlation between the pay levels of senior managers of listed companies and the company's operating performance.

Yan Chen[5] (2006) took the companies which listed in 2004 in Shenzhen and Shanghai as the research object, building least-squares linear regression model from the aspects of corporate performance, ownership structure arrangement and board government to study the impact on internal governance mechanisms of company management compensation. The conclusion was that the corporate performance, the proportion of state-owned shares, the size of the board, and two jobs concurrently all had a significant impact on Executive Compensation.

Sha Dai[6] (2007) took the listed companies in Shenzhen and Shanghai Stock Exchange from Hubei and Guangdong provinces as research object to examine the remuneration of senior executives. The executives' remuneration in Guangdong was significantly more than in Hubei, which indicated that a significant difference really exists between executive pay and the company's compensation contract in these two areas.

Jun Yue[7] (2007) took 105 listed companies in electronics as research object, finding that China's listed companies executive compensation reform and incentives building not only did it have scores, but also have problem.

Through the above review of domestic and international, we could find that the concluded is roughly the same whether domestic or foreign. Sometimes their conclusions are conflicting. Genfu Feng and Huifang Wang[8] (2002) considered that market factors, company-specific factors and specific conditions will have an impact on the conclusions in addition to results beyond measure selection.

\section{Model Selection and Data Specification}

Econometric model. This paper chooses a linear regression model and a binary linear regression model to examine the relation between executive compensation and corporate performance, the model is as follows:

$$
\begin{aligned}
& \mathrm{SGR}=\alpha_{0}+\alpha_{1} \mathrm{GP}_{1}+\varepsilon \\
& \mathrm{SGR}=\alpha_{0}+\alpha_{1} \mathrm{GP}_{1}+\alpha_{2} \mathrm{GP}_{2}+\varepsilon
\end{aligned}
$$


Among them, SGR is the sustainable growth rate, which represents the corporate performance, GP represents the executive compensation, respectively represented by $\mathrm{GP}_{1}$ (per capita paid executives) and $\mathrm{GP}_{2}$ (executive shareholding). The paper will take the regression analysis on $\mathrm{GP}_{1}$ and $\mathrm{GP}_{2}$ respectively, thus further comparative analysis of the two variables, in order to reach a more detailed analysis of the index.

Data specification. This paper selected all the A-share listed companies of Shanghai and Shenzhen stock markets as samples. Because of listed companies are public company, they have a mandatory provisions of information disclosure and governance, which is easy access to research data. The data for study comes from CSMAR database in 2012. In order to guarantee the validity of the data, the paper eventually selected 973 companies' data as the study sample after excluding abnormal samples.

\section{Empirical Analysis}

Descriptive statistical Analysis.

Table.1 Descriptive statistical analysis

Note: Multiple modes exist. The smallest value is shown.

\begin{tabular}{ccccc}
\hline & & $\begin{array}{c}\text { Sustainable growth } \\
\text { rate } \\
(\text { SGR })\end{array}$ & $\begin{array}{c}\text { Executive } \\
\text { compensation } \\
\left(\mathbf{G P}_{\mathbf{1}}\right)\end{array}$ & $\begin{array}{c}\text { Executive shareholding } \\
\left(\mathbf{G P}_{\mathbf{2}}\right)\end{array}$ \\
\hline $\mathbf{N} \quad$ Valid & 973 & 973 & 973 \\
$\mathbf{4}$ & Missing & 0 & 0 & 0 \\
Mean & 0.01851305257702 & 31.67 & 0.00152353703201 \\
Median & 0.01346784622000 & 25.19 & 0.00000000000000 \\
Std. Deviation & 0.017589399564523 & 23.576 & 0.026935001379945 \\
Variance & 0.000309386977040 & 555.806 & 0.000725494299338 \\
Range & 0.138886609922 & 175 & 0.624275018868 \\
Minimum & 0.000042983000 & 4 & 0.000000000000 \\
Maximum & 0.138929592922 & 179 & 0.624275018868 \\
\hline
\end{tabular}

All in all, China's listing Corporation executives pay compared with foreign countries still exists a relatively large gap. The average compensation of listed companies executives is $¥ 316,700$, while in 1992, general manager of medium-sized companies in America paid an average of $\$ 717,237$, $\$ 439,441$ in UK and $\$ 390,723$ in Japan $^{[9]}$. The income gap between executives is obvious. The highest is 44.75 times of the lowest. The variance of executive compensation is 555.806, which has great volatility.

From Table.1 we can also obtain the sustainable growth of listed companies is still very low. The highest is only 0.138929592922 and the lowest is 0.000042983 . The gap is huge and the level of development is extremely unbalanced. The arithmetic mean of all samples is $1.85 \%$, which is lower than the average industry cost profit margin and national economic growth rate. Senior management shareholding ratio is $65.88 \%$ and the proportion is relatively high, which indicates the equity incentive widely used in western works well in China.

In addition, as to senior shareholding, the highest is $62.43 \%$, the lowest is $0.00000279 \%$ and the arithmetic average is $1.99 \%$. So there is a huge difference among the listed corporation executives and the average level is relatively low, which indicates its incentive effect is limited. According to the statistics, the sustainable growth rate of executive stockholding company is $1.89 \%, 6.37 \%$ 
higher than the non-executives stockholding company, which illustrates the company performance of executive stock ownership shows better.

Regression Analysis.

Table.2 Regression analysis of the sample

Note: All requested variables entered, Dependent Variable: SGR

\begin{tabular}{cccc}
\hline Model & Variables Entered & Variables Removed & Method \\
\hline 1 & $\mathbf{G P}_{\mathbf{1}}(\mathbf{a})$ & -- & Enter \\
2 & $\mathbf{G P}_{1}, \mathbf{G P}_{2}(\mathbf{a})$ & -- & Enter \\
\hline
\end{tabular}

Table. 3 Analysis of variance of the sample

Note: Predictors: (Constant), $\mathrm{GP}_{1}, \mathrm{GP}_{2}$, Dependent Variable: SGR

\begin{tabular}{ccccccc}
\hline & Model & Sum of Squares & df & Mean Square & F & Sig. \\
\hline \multirow{2}{*}{$\mathbf{1}$} & Regression & 0.028 & 2 & 0.028 & 98.602 & $0.000(\mathrm{a})$ \\
& Residual & 0.273 & 970 & 0.000 & -- & -- \\
& Total & 0.301 & 972 & -- & -- & -- \\
\hline \multirow{2}{*}{$\mathbf{2}$} & Regression & 0.035 & 2 & 0.017 & 63.210 & $0.000(\mathrm{a})$ \\
& Residual & 0.266 & 970 & 0.000 & -- & -- \\
& Total & 0.301 & 972 & -- & -- & -- \\
\hline
\end{tabular}

Table.4 Correlation analysis of the sample

Note: Dependent Variable: SGR

\begin{tabular}{ccccccc}
\hline \multirow{2}{*}{ Model } & \multicolumn{2}{c}{$\begin{array}{c}\text { Un-standardized } \\
\text { Coefficients }\end{array}$} & $\begin{array}{c}\text { Standardized } \\
\text { Coefficients }\end{array}$ & \multirow{2}{*}{$\mathbf{t}$} & Sig. \\
\cline { 2 - 5 } & $\mathbf{B}$ & Std. Error & Beta & & \\
\hline \multirow{2}{*}{$\mathbf{1}$} & (Constant) & 0.011 & 0.001 & -- & 12.593 & 0.000 \\
\hline & $\mathbf{G P}_{\mathbf{1}}$ & 0.000 & 0.000 & 0.295 & 9.929 & 0.000 \\
\hline \multirow{2}{*}{$\mathbf{2}$} & (Constant) & 0.011 & 0.001 & -- & 12.805 & 0.000 \\
& $\mathbf{G P}_{\mathbf{1}}$ & 0.000 & 0.000 & 0.295 & 9.756 & 0.000 \\
& $\mathbf{G P}_{\mathbf{2}}$ & 0.099 & 0.020 & 0.152 & 5.034 & 0.000 \\
\hline
\end{tabular}

Table. 2 shows that all the variables are included in the scope of the study. From the variance analysis results showed in Table.3: SSR=0.028, SSE=0.273, SST=0.301, MSR=0.028, $\mathrm{MSE}=0.00028, \mathrm{~F}=98.601688$ and $\mathrm{P}<0.05$, it can be considered that the linear regression relationship between executive compensation and the sustainable growth rate are significant. The $T$ test of the regression model got from Table.4 are respectively 12.5931332332367 and 9.92983830924569 , and its corresponding probability are both less than 0.05 , so the significant test can be passed. Then the significant linear regression model of the relationship between executive pay and corporate performance is as follows:

$$
\mathrm{SGR}=0.000223 \times \mathrm{GP}_{1}+0.0113
$$


Then it can be confirmed that there exists the significant positive correlation between Executive compensation and corporate performance.

From the analysis conclusion, it can be seen that $\mathrm{R}^{2}$ increased $25 \%$ after adding the variable of executive shareholding, which means the fit of the models has been greatly improved. What's more, $\mathrm{F}=63.210$ and $\mathrm{P}<0.05$, test can be passed, that is to say the linear relationship of the variables is significant. And all the variables have passed the T test, which prove that $\mathrm{SGR}, \mathrm{GP}_{1}$ and $\mathrm{GP}_{2}$ exists the linear correlation. Their linear regression model is as follows:

$$
\mathrm{SGR}=0.00022 \times \mathrm{GP}_{1}+0.099 \times \mathrm{GP}_{2}+0.11
$$

The coefficient of the executive shareholding is 0.099 , which is 450 times that of per capita paid executives. It indicates that the influence of executive shareholding on corporate performance is 450 times stronger than per capita paid executives, which is consistent with the theoretical analysis.

\section{Conclusions}

The paper select 973 A-share listed companies in Shanghai and Shenzhen stock markets as samples, sustainable development ratio as company performance index, descriptive statistical methods and regression analysis to be basic research methods. And study on the relationship between executive compensation and corporate performance in listing corporation. Through empirical study, the following conclusions are drawn: On one hand, executive compensation and corporate performance are significantly positive correlation. This shows that the compensation incentive development of China's listing corporation is more health. Though compared with the developed countries there is still a big gap, pay remuneration to the executives of listed companies show the incentive effect. On the other hand, executive shareholding and corporate performance was significantly positive correlation. And the incentive effect is more significant. But executive shareholding ratio is still very little, which also not fully play the function of equity incentive.

Finally, according to the empirical research $t$ conclusions, the paper proposes some appropriate policy recommendations:

Firstly, an effective pay-performance contract should be designed in order to solve the conflict of interest of agent problem effectively.

Secondly, the senior executives' ESOP of the listing corporation needs to improve. Company law should eliminate the legal obstacles for listing corporation stock incentive.

Thirdly, government should continue to develop an effective and stable capital market. Securities regulatory authorities should strengthen the market norms, promote the concept of rational investment, prudent regulate market supply and demand, to make the stock market in a stable and efficient direction.

Lastly, listing corporation need to further improve their internal governance structure.

\section{References}

[1] BARRO J R. Pay, Performance and Turnover of Bank ECOs[J]. Journal of Labor Economies, 1990(4):448.

[2] Garen J E. Executive Compensation and Principal Agent Theory[J]. Journal of Political Economy,1994(6):1175-1199.

[3] Mehran H. Executive Compensation Structure, Ownership and Performance[J]. Journal of Financial,1995(2):163-184. 
[4] Gang Wei. Senior management incentive and operating performance of listed companies[J]. Economic Research Journal,2000(3):32- 39.

[5] Yan Chen. Empirical research on Company Performance, Corporate Governance and Executive Compensation[J]. Journal of Central University of Finance \& Economics,2006(04):92-96.

[6] Sha Dai. Empirical study of executive compensation and regional differences[J]. Research and Decision-Making,2007(04).

[7] Jun Yue. The correlation of equity structure, remuneration incentive and corporate performance[J]. Collected Essays on Finance and Economics,2007(07):89-96.

[8]Genfu Feng, Huifang Wang. Reviews of the theoretical and empirical study on listing corporation performance[J]. Journal of Northwest University,2002(01):29-33.

[9] Lei Gao, Shunlin Song. Executive compensation incentive and corporate performance, the evidence from Chinese listed companies[J]. Finance \& Economics, 2007(04):63-69. 